www.jmscr.igmpublication.org

Index Copernicus Value: 79.54

ISSN (e)-2347-176x ISSN (p) 2455-0450

crossrefDOI: https://dx.doi.org/10.18535/jmscr/v7i3.69

\title{
A Study of Broncheoalveolar Lavage (BAL) In Diagnosis of Respiratory Disease in Tertiary Care Hospital
}

\author{
Authors \\ Ekta Pandey, Kalaivani Seivi S*, Erli Amel Ivan \\ Department of Pathology, Sri ManakulaVinagyar Medical College, Kalitheerthalkuppam, \\ Puducheery, 605107, India \\ *Corresponding Author \\ Dr Kalaivani Selvi S \\ Assistant Professor, Department of Pathology, Sri Manukula Vinayagar Medical College, \\ Kalitheerthalkuppam, 605107, India \\ Email: klvnselvi@yahoo.co.in, Mobileno-9789545249
}

\begin{abstract}
It is a prospective observation study that evaluates use of bronchoalveolar lavage (BAL) for the diagnosis of infective and malignant pulmonary pathologies. We studied BAL samples in 52 consecutive patients from period of January 2017 to June 2018. We had 7 patients with pulmonary malignancy, proven on biopsy. Whereas BAL yielded only 4 positive cases. Sensitivity, specificity, positive predictive value and negative predictive value of BAL for diagnosis of malignancy were $57.14 \%, 95.55 \%, 66.66 \%$ and $93.47 \%$ respectively.

Keywords: Bronchoalveolar lavage, lung cancer, pulmonary infection.
\end{abstract}

\section{Introduction}

It is sampling beyond tertiary bronchioles till alveolar spaces. It is a diagnostic procedure in which bronchoscope is passed through the mouth or nose into the lungs and fluid is squirted into a small part of the lung and then collected for examination. ${ }^{[1]}$ It provides information on the status of respiratory tract in small bronchi beyond reach of bronchoscopic brush. It is very sensitive and specific to pick up bronchoalveolar carcinoma. Bronchoalveolar lavage is used for diagnosis of interstitial lung disease, broad spectrum of inflammatory and infectious lung diseases, opportunistic infections and malignant pathologies. ${ }^{[2]}$

\section{Aims and Objective}

We tried to evaluate the role of BAL in diagnosis of respiratory diseases and its role in diagnosis of lung carcinoma.

\section{Material and Methods}

It is a prospective observational study of bronchoalveolar lavage (BAL) in patients presenting with pulmonary symptoms. BAL sample in lung cancer patient was correlated with biopsy or brush cytology.

\section{Inclusion criteria}

All patients above who underwent bronchoscopic lavage for complaints of cough, hemoptysis, dyspnoea on exertion or $\mathrm{X}$ ray/computed 
tomography picture of lung mass/ infiltrate were included in the study.

\section{Exclusion criteria}

Patients previously treated for any malignancy or under treatment for the same.

\section{Methodology}

We studied serial BAL finding of 52 cases, fulfilling inclusion criteria, from period of January 2017 to June 2018. Study was conducted in tertiary care hospital. Lavage was taken from the affected segment and was sent for malignant cytology, bacterial, tuberculosis and fungal culture. At the same time patients underwent brush cytology or computed tomography guided biopsy if any visible lesion. We compared the result of BAL with brush cytology and biopsy.

\section{Observation and Result}

The present study included 52patients between the periodJanuary 2017 to June 2018. The maximum number of patients were in age group of 31 to 40 years, $(28 \%)$. Male to female ratio was 58:42. On BAL cytology we found 6 malignant cases, out of which 4 were true positive and 2 were false positive when compared with brush cytology/biopsy. Out of two false positive on BAL one patient turned out to be squamous metaplasia whereas another had type 2pneumocyte hyperplasia. We had 3 false negative on BAL, biopsy of two patients was adenocarcinoma and one was poorly differentiated carcinoma. Sensitivity of BAL for diagnosing malignancy was $57.14 \%$, specificity was $95.55 \%$, positive predictive value and negative predictive value were $66.66 \%, 93.47 \%$ respectively. Similar results have been seen in other articles also. ${ }^{[3,4]}$

\begin{tabular}{|l|c|}
\hline BAL & Values \\
\hline Sensitivity & $57.14 \%$ \\
\hline Specificity & $95.55 \%$ \\
\hline Positive predictive value & $66.66 \%$ \\
\hline Negative predictive value & $93.47 \%$ \\
\hline
\end{tabular}

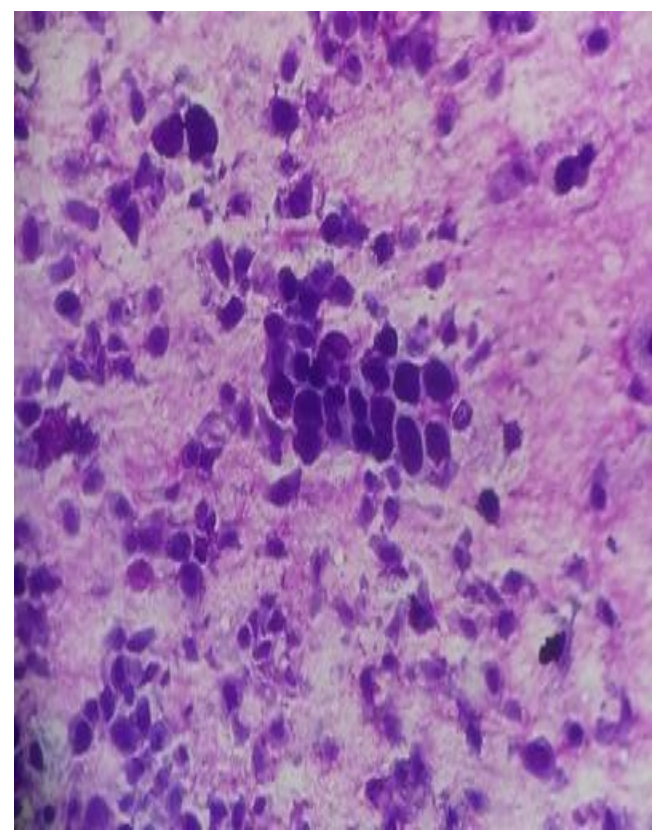

Figure 1: Cytological smear showing scattered polygonal cells, lymphocytes and few macrophages (MGG x10) and Clusters of tumour cells (MGG x40).

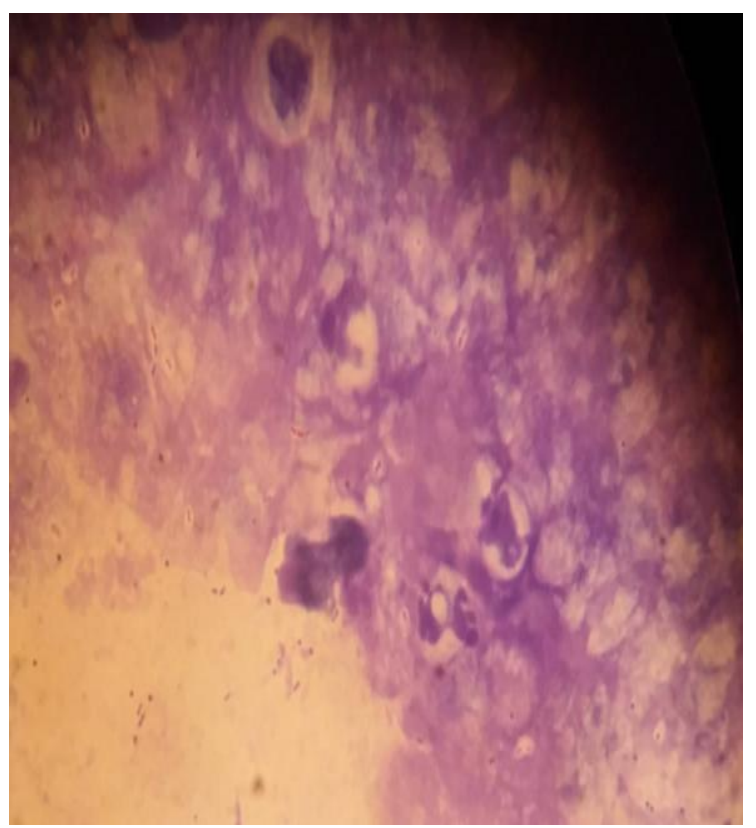

Figure 2- Shows AFS Positivity

\section{Discussion and Conclusion}

BAL cytology is an integral part of work up of a patient presenting with respiratory symptoms. ${ }^{[5]}$ It provides us sample for diagnosis of infection, malignancy and also help in determining antimicrobial sensitivity for organism grown. It is a complementary test in diagnosis of malignancy. ${ }^{[6]}$ Biopsy is any time better than BAL cytology 
for malignancy because of utilization of biopsy sample for typing and immunohistochemistry. But BAL cytology is helpful in ruling out malignancy because of its high specificity and negative predictive value. FNAC and histopathology are complementary to each other, in yielding an accurate diagnosis of various broncheoalvealor lesions.

\section{References}

1. Collins AM, Rylance J, Wootton DG, Wright AD, Wright AK, Fullerton DG, Gordon SB. Bronchoalveolar lavage (BAL) for research; obtaining adequate sample yield. Journal of visualized experiments: JoVE. 2014(85).

2. Springmeyer SC. The clinical use of bronchoalveolar lavage. Chest. 1987 Nov 1;92(5):771-2.

3. Tomar V, Vijay N, Nuwal P, Dixit R. Comparative study of bronchoalveolar lavage, bronchial brushing, and FNAC in diagnosing malignant neoplasms of lungs. Journal of cytology. 2016 Oct;33(4):210.

4. Gaur DS, Thapliyal NC, Kishore S, Pathak VP. Efficacy of broncho-alveolar lavage and bronchial brush cytology in diagnosing lung cancers. Journal of cytology. 2007 Apr 1;24(2):73.

5. Gharsalli H, Mlika M, Sahnoun I, Maalej S, Leila DE, El Mezni F. The utility of bronchoalveolar lavage in the evaluation of interstitial lung diseases: a clinicopathological perspective. In Seminars in diagnostic pathology 2018 Aug 24. WB Saunders.

6. Sareen R, Pandey CL. Lung malignancy: Diagnostic accuracies of bronchoalveolar lavage, bronchial brushing, and fine needle aspiration cytology. Lung India: official organ of Indian Chest Society. 2016 Nov;33(6):635. 